\title{
Necessity Is the Mother of Invention for Research and Extension Agenda of Rubber Smallholders
}

\author{
Rahim Md. Sail ${ }^{1}$, Sucihatiningsih Dian Wisika Prajanti ${ }^{2}$ and Hanina Halimatusaadiah Hamsan $^{3}$ \\ 1. Department of Professional Development and Continuing Education, Faculty of Educational Studies, Universiti Putra Malaysia, \\ Serdang 43400, Selangor, Malaysia \\ 2. Department of Economic Development, Faculty of Economics, Semarang State University, Kota Semarang, Jawa Tengah 50229, \\ Indonesia
}

3. Department of Social and Development Sciences, Faculty of Human Ecology, Universiti Putra Malaysia, Serdang 43400, Selangor, Malaysia

\begin{abstract}
Researchers and extensionists would pursue their interests to develop new inventions and encourage rubber smallholders to adopt new technology and practices to increase production of their holdings. Three interrelated systems, research and development (R\&D) system, extension/delivery system and client (smallholders) system, are responsible to make the rubber industry viable and dynamic. The extension system is also encouraged to identify and carry out related research activities besides its own core function to enhance clients' understanding and to use the findings as basis to plan effective strategies for implementation. Knowledge acquisition among clients is critical in capacity building process. With knowledge, clients tend to develop favorable attitude and use it to develop specific skill to practice recommended technology and new practices. Necessity is the mother of invention in times of need, especially when rubber price is low. Researchers, extensionists and smallholders are "forced" to collaborate and become creative to find alternative ways and uses of natural rubber to increase demand of the commodity. When natural rubber price is low, funding for research needs to be maintained at current level, or in some cases, funding is increased to ensure that the industry is not void of new technology and new products. The main goal of the rubber industry is to ensure that new technology and practices are continuously being generated and developed by researchers to be adopted by rubber smallholders. The adoption of new technology and practices by smallholders ensures that production of natural rubber continues to increase, while income of smallholders is maintained or increased at an appreciative level to offset low rubber prices. There is an inclination in the rubber industry that when the commodity's price is low, activities and programs related to research and dissemination of research results would follow to be reduced, resulting in stagnation and opportunities for future growth of the industry. The National Blue Ocean Strategy (NBOS) should be used to harness expertise in research among researchers of local universities, as well as to cooperate among extensionists from agencies at state and national levels to help disseminate research results. The NBOS can reduce cost, and has bigger impacts and wider applications of natural rubber for local and international markets.
\end{abstract}

Key words: Necessity, research and extension agenda, rubber smallholders.

\section{Introduction}

Past research and development (R\&D) had shown that natural rubber had excellent physical, chemical and biological properties, which had been used extensively by scientists and technologists in the advancement of engineering-related products in industries. Natural rubbers' versatility, adaptability

Corresponding author: Rahim Md. Sail, Ph.D., research fields: extension education and human resource development (HRD). and high quality have made it a natural choice for many popular products, such as tyres, gloves, rubber-bonded steel laminate bearings for its ability to store more elastic energy than steel [1]. The extensive uses and applications of natural rubber in the industrial setting create significant impacts on the demand and supply of the commodity. The higher demand would usually increase commodity price, and thus would benefit those involved in the production of the commodity. 
In order to increase the production of natural rubber, both upstream and downstream research activities need to be expanded and conducted. The upstream research activities, such as developing new, high yielding and diseases resistant rubber clones, new and innovative yield stimulants and good agricultural practices (GAP) are some examples of research activities that need to be conducted to increase yield of rubber per hectare. On the other hand, downstream research activities need to be continuously carried out to find new and other uses of natural rubber at reducing cost of production with high quality products produced, compared to its main competitor, the synthetic rubber. One of the most interesting downstream research results is the usage of rubber cup lumps to substitute tarmac in the construction of roads. Roads made of rubber cup lumps are much cheaper in maintenance cost and much safer than using the tarmac materials [2, 3].

Research programs in the rubber industry become the lifeline to ensure sustainability and growth of the industry. This lifeline needs to be done regardless of price of the commodity in the world market, or else the industry will become obsolete, rendering thousands of smallholders of getting reduced monthly incomes. In addition, new technology and practices generated and developed by research programs need to be transferred by extensionists to be adopted by smallholders. This is in line with the idea postulated by Rogers' Diffusion of Innovations theory [4]. The research, extension and client (rubber smallholders) become three important agendas that need to be addressed collaboratively to make a dynamic and sustained rubber industry for short and long term growth.

\section{Profile of Rubber Smallholders}

Before going through further on the research and extension agenda, it would be helpful to reflect on the profile of rubber smallholders, which constitutes some 500,000 of them, planting about one million hectares of rubber and producing about 900,000 tons of rubber per year. Slightly, more than one-half $(56.1 \%)$ of the smallholders own less than 2 ha, while 36.9\% own 2-4 ha and only 7\% own more than 4 ha. About two-thirds (65.4\%) of smallholders are 51-60 years old and $70.4 \%$ have primary school education. The majority of smallholders (81.7\%) have single ownership of rubber land, $70 \%$ of them operate their land on their own and $61.1 \%$ of them are full-time smallholders [5-8].

\section{Research, Extension and Clients Linkage Systems}

Three interacting systems of research, extension and client work hand-in-hand to ensure each system functions and support each other to achieve individual's system goals, as well as the overall systems' goals. The systems are: (1) the research system, represented by the Malaysia Rubber Board (MRB) for the rubber industry; (2) the extension system, represented by the Rubber Industry Smallholders Development Authority (RISDA); (3) the clients system, represented by some 500,000 smallholders scattered throughout Malaysia. Fig. 1 illustrated the interrelationships of the three systems, where the research system generates and develops new technology or new practices or new ideas for the rubber industry to be picked up by the extension system for delivery to the client system for adoption.

The R\&D system in the rubber industry consists of upstream and downstream research agenda, where both streams are required to meet the goal of making the rubbery industry a viable and dynamic industry. The upstream research agenda usually focuses on developing healthy holdings through good planting materials, good agricultural practices for smallholders to adopt in their holdings for higher productivity and higher quality of products produced. Also, the upstream research agenda focuses on developing new knowledge and understanding on the physiological, biological and genetic make-up of rubber wood, latex and other parts of a rubber tree to expand the horizon of 


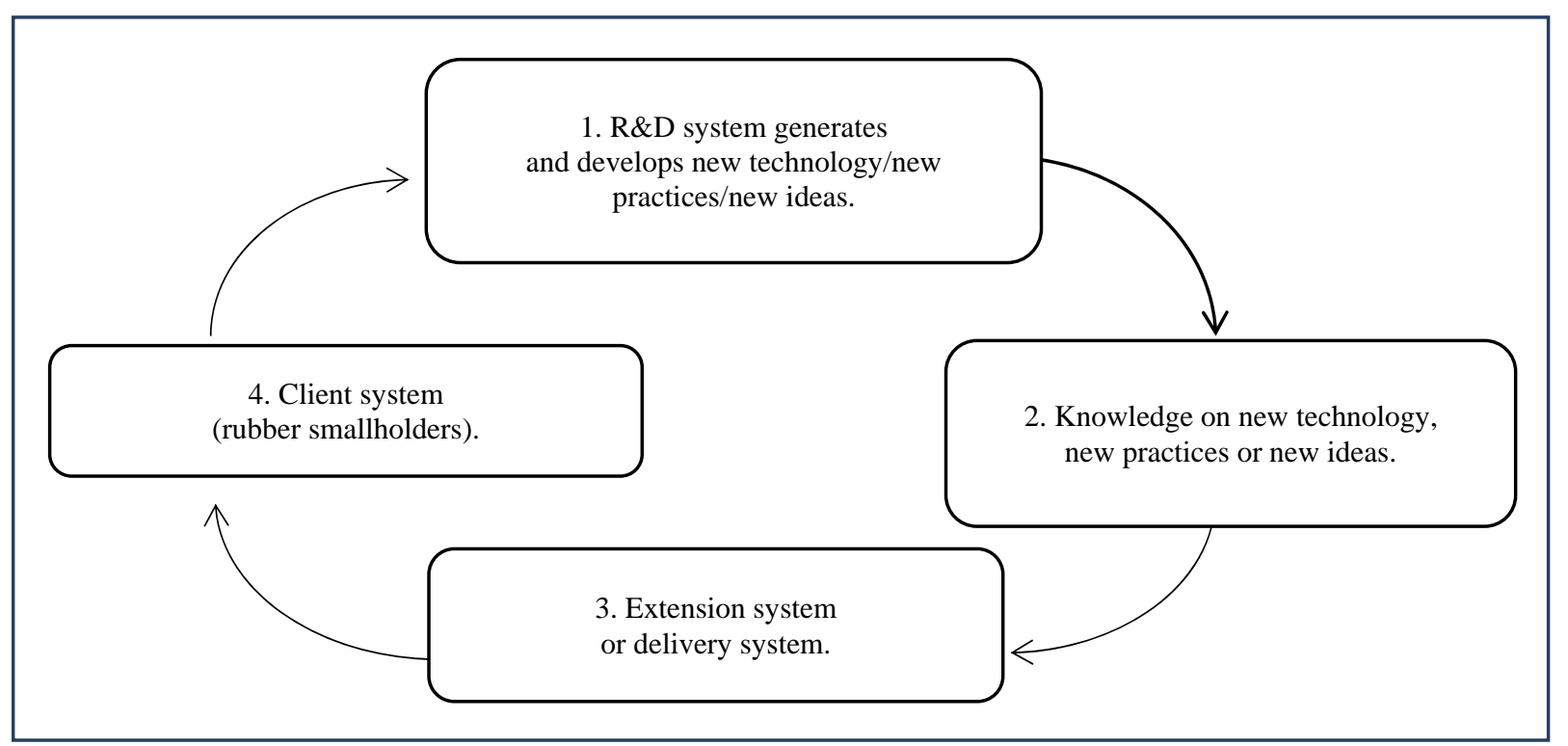

Fig. 1 The research-extension-client linkage system.

possibilities and potentials to develop new products and new uses of rubber [9]. Another aspect of upstream research agenda would be to intensify and diversify possibilities and potentials of planting other crops and rearing livestock in immature and mature rubber holdings. This would allow one or two other sources of supplementary incomes for smallholders, besides rubber.

The focus on generation and development of new products and new uses of natural rubber from the research agenda, especially the downstream research activities, is to produce less expensive and superior quality products being able to compete with their competitors. When rubber price is low, research agenda needs to be expanded and researchers need to be encouraged to become creative and pursue their short and long term goals. This is not in line with the popular belief that when funds become scarce, research activities need to be slowed down to accommodate budgeting constraints. In the situation of a dynamic rubber industry, especially when researchers are dealing with "fixed assets" of uneconomic-sized holdings, old age, hired labour and low technology adoption level among smallholders, funding for research needs to be continued and maintained at current level or higher even though rubber price is low. The generation and development of new products, new technology and new practices will avoid the rubber industry to become obsolete and make it still able to compete with competitor products $[10,11]$.

It is common knowledge that not all research efforts would end up with usable and viable products, but there is always a beginning in any research effort, especially in the understanding of the processes involved to be continued in future efforts. When this happens, researchers do not have to start from zero. They can upgrade, upscale and twist around ideas to find new ways to solve a problem.

The higher productivity and quality of products produced by smallholders and the engagement of smallholders in diversification of income generating activities in their holdings would offer higher returns to their activities, which would offset low prices of natural rubber. The extensive uses and application of natural rubber, both from the upstream and downstream products, would create significant impacts on the demand and supply of the commodity for local and outside consumption. The increase in demand and supply of natural rubber would, to some extent, stabilize its market price. The primary driving force for most new inventions is a "need" or a "gap" 
that requires one to fulfill it to acquire satisfaction and joy for doing it, as well as to avoid negative outcome and increase creative performance of researchers [12]. This is in line with the proverb "necessity is the mother of invention", where one becomes creative, works hard and is committed to achieve identified and sometimes unidentified goals. Give researchers a free hand with minimum control in a less bureaucratic environment to produce result.

The extension or delivery system plays an important and significant role in disseminating technology information generated and developed by research to be adopted by smallholders to increase productivity of holdings, as well as to improve quality of products produced. Another equally important role of the extension system is the development of smallholders' capacity to acquire knowledge, skill and to develop favorable attitudes towards improving their enterprises on their own [13]. The two roles of the extension system require competent extensionists able to discharge their duties and responsibilities to ensure that smallholders are adopting and practicing the latest technology in rubber production, as well as to encourage smallholders to venture into other income generating activities on their own initiatives. Regular in-service training program is a necessity and must be instituted by extension agencies to provide extensionists not only on technical and management knowledge and skill, but also on how to develop the capacity of smallholders with effective andragogical teaching and learning techniques [14]. Training programs for the extension system need to be funded adequately and conducted regularly, or else extensionists will be obsolete in terms of knowledge of the latest technology and practices available in rubber cultivation.

To be effective in the extension or delivery system, extensionists need to be: (1) competent in new technology and the latest good management practices within six months of their introduction; (2) competent in teaching and/or learning methodologies, especially those that are related to andragogy (facilitating adult learning); (3) competent in using and applying modern media to acquire new technology information and new practices from other sources locally, as well as abroad. Extension agencies need to audit and carry out training need analysis (TNA) for their extensionists to plan and execute an effective training program. Extensionists must also be trained with simple research techniques to enable them to acquire systematic feedback from clients, as well as to access the effectiveness of their own work as basis for future performance improvement. The extension system (and the research system as well) should carry out studies on competency and performance of extensionists in transfer of technology, as well as in capacity building of smallholders. The findings of this study are useful to gauge current levels of competency and performance of extensionists, which would become a credible basis for planning and execution of future training programs.

The client system becomes the focus of both the research and the extension systems in the rubber industry, where both systems are geared towards improving efficiency and productivity of smallholders through transfer of technology and good agricultural and management practices. The main goal of research and extension systems in the rubber industry is to improve smallholders' well-being or welfare, involving both material sufficiency and non-economic aspect of living, such as health and education. Material sufficiency and smallholders' welfare must be supplemented and complemented with acquisition of technical knowledge, inculcation of favorable attitudes, development of appropriate skills and practice to affect smallholders' economic, social well-being and quality of life. The economic aspect and the capacity building of smallholders' development are essential to be carried out to ensure that they would be more committed to succeed on their own. This concept and approach would avoid smallholders to become perpetual dependent on others, 


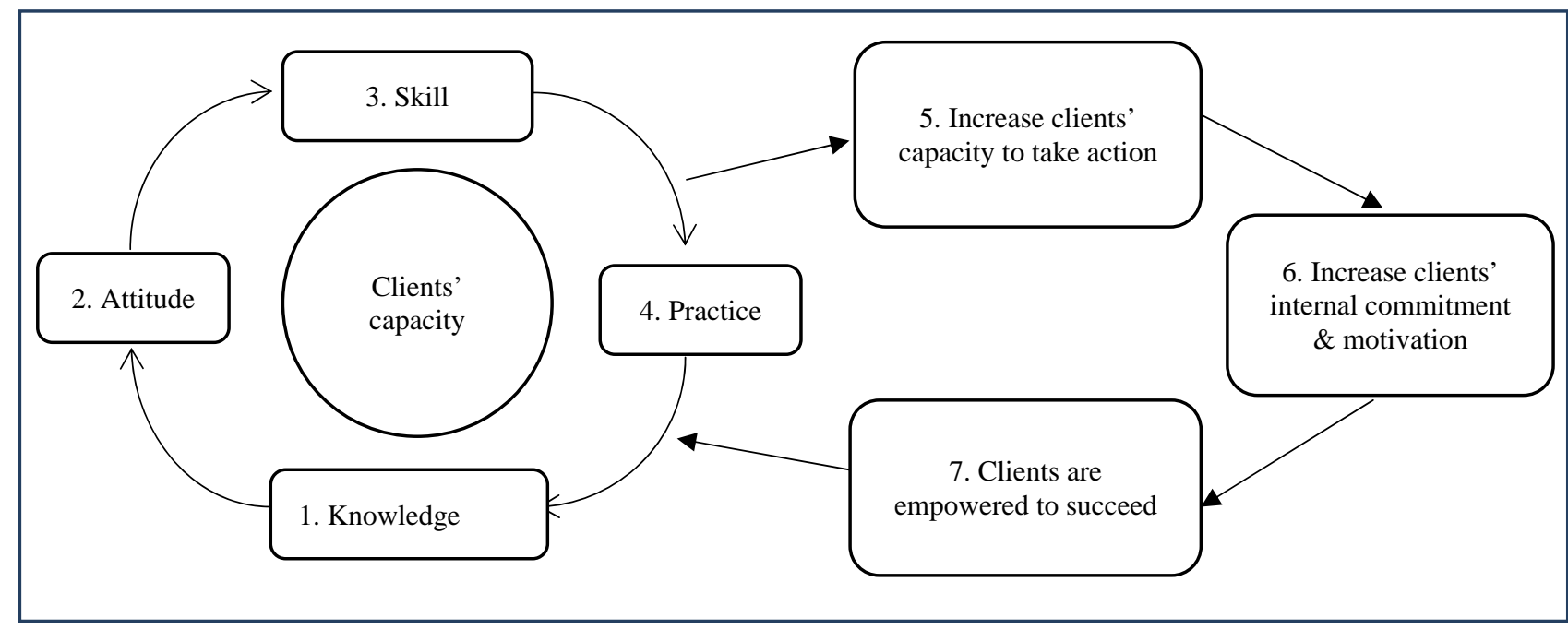

Fig. 2 Clients' capacity building for increasing internal commitment and motivation to succeed.

which is undesirable in the short, as well as in the long-term development goals. How to avoid smallholders from becoming perpetual dependent on others for their own development? It is not an easy question to answer, especially when the situation is complex and factors influencing it intertwine with customs and beliefs of the population. Nevertheless, it is not impossible, given time and space, to overcome this dependency syndrome. Four inter-related factors have been identified when implemented with full participation of smallholders, which would help reduce the problem of dependency. These factors are: (1) acquisition of life skill knowledge; (2) inculcation of favorable attitude; (3) development of generic and specific skills; (4) adoption and implementation of recommended practices for efficiency and productivity of enterprises.

The acquisition of knowledge, whether it is technical or problem-solving and decision-making skills, becomes an important building block for initiating smallholders' performance to upgrade their socio-economic well-being and quality of life. Knowledge is also a prerequisite for inculcating positive attitude, which would lead to the development of specific skill to practice the required change for their economic growth and development. Implied in this concept and practice is a continuous learning process to acquire knowledge and skills, which become the foundation for capacity building of smallholders to succeed with little or no help from others and thus, reduce the issue of dependency. Fig. 2 illustrated the development of clients' capacity to increase internal commitment and motivation to be empowered with full participation in all the processes involved from basic acquisition of specific knowledge to full implementation of a program [15].

A comparative study on the patterns of adoption of new technology and practices among smallholder groups should be done to determine the "whats" and "whys" certain smallholder groups adopt new technology and practices faster than others in immature, mature and old holdings. The findings from this study would shed some light on methodological issues in extension education work, especially methods of information dissemination, as well as to determine the focus and priorities of smallholders in rubber cultivation.

\section{Conclusions}

"Necessity is the mother of invention" is a proverb appropriately described present day situation of natural rubber to offset low rubber prices and low incomes of rubber smallholders. All stakeholders in the rubber industry have to think out of the box, work 
hard, be creative and committed in programs and activities they are engaged in. The research, extension and client systems have to collaborate to solidify their positions and strategize their programs to achieve their common goals, that is, to increase production, utility and demand of natural rubber. This collaboration is critical to ensure that the price of natural rubber would increase to a reasonable level and would sustain for a long period of time.

Intensifying and diversifying research programs on natural rubber, especially downstream research activities need to be expanded and well-funded in times of low rubber prices. Researchers should be given appropriate incentives for their inventions and they should not be pressured to come up with "quick fix" solutions to existing problems. They need time, space and flexibility to carry out the work creatively.

For the extension system, extensionists need to be equipped with the latest technology and good agricultural practices, besides having a working knowledge on capacity building of smallholders. In addition to these competencies, extensionists need to be well-versed in andragogical techniques to be able to deliver capacity building and technical information to their clients effectively.

The research, extension and client systems are intricately related to each other. Each system must be strong in itself and supports the functions of the other two systems in a symbiotic relationship for mutual benefits. The National Blue Ocean Strategy (NBOS) should be used in the research and extension systems to collaborate with each other and with other research organizations at federal and state levels, not only for cost saving, but also for bigger impacts and wider applications of natural rubber.

\section{References}

[1] Ab-Malek, K., and Roberts, A. D. 2013. From Pelham to Penang: Natural Rubber Bearings for Civil Engineering. Kuala Lumpur, Malaysia: Malaysian Rubber Board.

[2] Presti, D. L. 2013. "Recycled Tyre Rubber Modified Bitumens for Road Asphalt Mixtures: A Literature Review." Construction and Building Materials 49:
863-81.

[3] Wulandari, P. S., and Tjandra, D. 2017. "Use of Crumb Rubber as an Additive in Asphalt Concrete Mixture." Procedia Engineering 171: 1384-9.

[4] Rogers, E., ed.. 2004. Diffusion of Innovations. 5th ed..

[5] Sail, R. M., and Muhamad, M. 1994. "Factors Associated with Non-adoption of Technology by Rubber Smallholders.” Pertanika Journal Social Science \& Humanities 2 (1): 29-41.

[6] Sail, R. M. 2016. Extension Education for a Developed Malaysia: Relevance and Its Applicability for Clients' Capability and Capacity Building: Enhancing Green Agriculture. Bangi, Malaysia: University Putra Malaysia.

[7] Sail, R. M., and Ahmad, M. 2009. Enhancing Socio-Economy of Rubber Smallholders through Effective Transfer of Technology. Kuala Lumpur, Malaysia: Rubber Research Institute of Malaysia.

[8] Sail, R. M. 2002. "Adoption of Research Results: Effectiveness of Transfer of Technology to Rubber Smallholders.” Presented at the IRRDB Liaison Officers Meeting, Kuala Lumpur, Malaysia.

[9] Sail, R. M. 2011. "Empowering of Rubber Smallholders in Technology Adoption: Roles of Research and Extension Agencies.” Presented at the 2nd Scientific and Economic Advisory Council (SEAC) Meeting, Malaysian Rubber Board, Kuala Lumpur, Malaysia.

[10] Sail, R. M., Kobat, R. B. S. R. S., Ibrahim, A. G., Tasi, A. Z. M., Said, I., Noor, M. Y. M., Idris, K., Kadir, M. H. A., and Suandi, T. 1993. Transfer of Technology: Tracing through the Path of Technology Flow from Research to End Users. Serdang: Rubber Research Institute of Malaysia and University Putra Malaysia.

[11] Sail, R. M., Kobat, R. B. S. R. S., Ibrahim, A. G., Muhammad, A. F., Muhammad, M., Tahir, M. H. M., Noor, M. Y. M., and Salleh, W. M. W. 1990. From Smallholder' Practices, Constraints and Needs to Appropriate Technology Generation, Development and Adoption: The Case of Rubber Smallholdings in Penisular Malaysia. Research Report, Rubber Research Institute of Malaysia and Universiti Pertanian Malaysia, 188.

[12] Roskes, M., De Dreu, C. K., and Nijstad, B. A. 2012. "Necessity Is the Mother of Invention: Avoidance Motivation Stimulates Creativity through Cognitive Effort." Journal of Personality and Social Psychology 103 (2): 242-56.

[13] Sail, R. M. 2016. "Capacity Building as an Enabler for Sustained Economic Growth and Development of Rural Communities: Roles of Research and Extensions Agencies." Paper Presented at the International Conferences on Economics, Education, Business and Accounting (ICEEBA), Universitas Negeri Semarang, 


\section{of Rubber Smallholders}

Indonesia.

[14] Knowles, M. S., Holton III, E. F., and Swanson, R. A. 2014. The Adult Learner: The Definitive Classic in Adult Education and Human Resource Development. 8th ed..
London: Routledge.

[15] Argyris, C. 2001. "Empowerment: The Emperor's New Clothes.” In Creative Management, edited by Henry, J. London: Sage Publications, 195-201. 